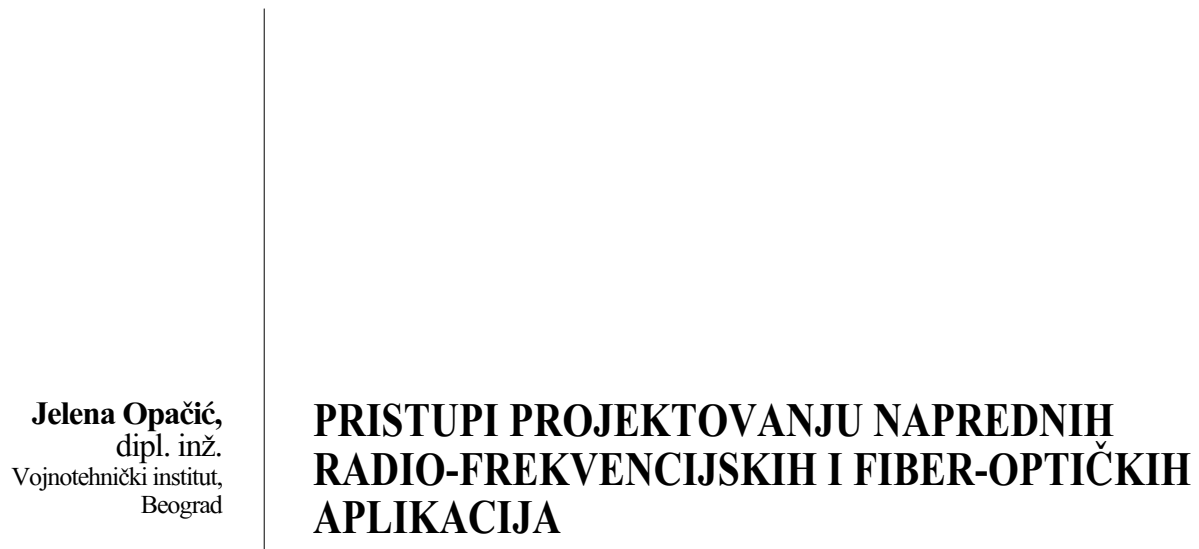

UDC: $621.3 .049 .77-03$

Rezime:

U radu su prikazane osnovne karakteristike savremenih materijala: silicijum-germanijuma (SiGe), galijum-arsenida (GaAs) i indijum-fosfida (InP), tehnika i tehnologija koje sa svojim osobinama predstavljaju podršku razvoju savremenim i budućim radio-frekvencijskim $(R F)$ i fiber-optičkim (FO) aplikacijama koje rade na sve višim frekvencijama $i$ radnim brzinama. Zahtevi tržišta, mogućnosti savremenih materijala i tehnologija diktiraju projektantima usavršavanje pristupa projektovanju sklopova, koje se ogleda kroz više nivoe integracije kola, nova pakovanja i testiranja integrisanih kola (IC).

Ključne reči: projektovanje, silicijum-germanijum, galijum-arsenid, indijum-fosfid, radio-frekvencijske aplikacije, fiber-optičke aplikacije, ekstremno visoke frekvencije.

\title{
DESIGN OF ADVANCED RADIO FREQUENCY AND FIBER OPTICS APPLICATIONS
}

Summary:

This paper contains elementary characteristics of materials such as silicon-germanium (SiGe), gallium-arsenide (GaAs) and indium-phosphide (InP), procedures and technologies which support developement of modern and future Radio Frequency (RF) and Fiber Optics (FO) applications operating at ever-higher frequencies and speeds. Market requirements, possibilities of modern materials and technologies dictate to designers improvement of the product design the access through higher levels of circuit integration, new packaging and testing of integrated circuits (IC).

Key words: design, silicon-germanium, gallium-arsenide, indium-phosphide, radio-frequency applications, fiber-optics applications, ultra high frequencies.

\section{Uvod}

U ovom radu je dat prikaz savremenog trenda razvoja RF (Radio Frequency) i FO (Fiber Optics) tehnologija $\mathrm{s}$ kojim se menja pogled i pristup projektovanju novih i budućih RF i FO aplikacija, sa ciljem da se čitaocima skrene pažnja na aktuelan pristup projektovanju sklopova i tendencije.

Iz ekspanzije širokopojasnog prenosa i bežičnih telekomunikacija proistekao je rad na sve višim frekvencijama EHF (Extremly-High Frequencies) i radnim brzinama. Uporedo s tim razvijala su se i saznanja o materijalima, tehnikama i tehnologijama koje mogu biti podrška razvoju naprednih RF i FO komunikacionih sistema. S obzirom na mogućnosti savremenih materijala i tehnologija i zahteve tržišta, od projektanata naprednih sistema zahtevaće se posedovanje širih znanja i iz oblasti materijala, tehnika i tehnologija, jer se samo kroz njihovu interakciju u 
procesu projektovanja i izrade sklopova može doći do odgovora na zahteve tržišta za novim proizvodima.

U polju žičanog prenosa teži se da se razvije nova generacija FO opreme koja će raditi na brzinama protoka od 40 $\mathrm{Gb} / \mathrm{s}$ i obezbediti infrastrukturu za uvođenje isplative širine propusnog opsega koja je potrebna za tekući video, video konferenciju u punom dupleksu i druge multimedijalne aplikacije. U polju bežičnog prenosa širokopojasni sistemi rade $u$ Ka opsegu (20 do $30 \mathrm{GHz}$ ) frekvencija i višem. V i W opsezi (60 GHz i više), prvenstveno jedini domen vojnih komunikacionih aplikacija, pojavljuju se kao alternativa za komercijalnu primenu.

Delovanje tržišta i mogućnosti koje pruža tehnologija diktiraju postavljanje zahteva za širim propusnim opsegom, manjim džiterom, snabdevanjem napajanjem i potrošnjom snage novih kola. Tako će se od projektanata novih kola naprednih RF sistema zahtevati da razumeju i koriste veliki broj novih tehnologija i tehnika uključujući i nove materijale, kao što su SiGe i InP, više nivoe integracije kola, nova pakovanja i testiranja. Projektantima ce biti potrebno da razumeju ja$\mathrm{ku}$ interakciju između izbora materijala, projekta čipa i efekata pakovanja, što sve zajedno utiče na osobine proizvoda.

RF zahtevi i potrebe tržišta pružaju projektantima budućih visokobrzinskih kola i dalje korišćenje mogućnosti koje pruža silicijum, najčešće upotrebljavani poluprovodnik u današnjim komunikacionim aplikacijama. Sledeća generacija uređaja većinom će biti zasnovana na jedinjenjima poluprovodničkih materijala među kojima cee biti SiGe, GaAs i InP. Svaki od materijala pruža i prednosti i nedostatke za projektante RF uređaja.
Sadržaj rada čine: kratak pregled materijala SiGe, GaAs i InP, sa osvrtom na integraciju kola i komponenti, pakovanja i testiranja integrisanih kola sa novim pristupom, i na razvojni program evropske komisije vezan za evoluciju CMOS (Complementary Metal-Oxide-Semiconductor - komplementaran metal-oksid-poluprovodnik) tehnologije.

\section{Silicijum-germanijum ( SiGe )}

SiGe je silicijumski derivat u kome se SiGe legura koristi da poboljša prenos nosioca u bazi standardnih silicijumskih bipolarnih tranzistora. Ovo umanjuje otpornost baze i poboljšava prolazno vreme (transit time) baze tranzistora. Time se poboljšavaju frekvencijske osobine $u$ poređenju sa standardnim silicijumskim elementima iste geometrije. Takođe, veliki deo kompleksnih kola i troškova proizvodnje strukture silicijuma mogu se proširiti na komponente za više frekvencije. SiGe poseduje visokofrekvencijske osobine koje se ogledaju u smanjenju veličine, uvećanju unutrašnjih polja i gustine struje i značajnom smanjenju probojnog (breakdown) napona. Tako je radni napon SiGe tipično ograničen na 1 VDC ili manje za aplikacije iznad $30 \mathrm{GHz}$.

Kako sa unapređenjima tehnološkog procesa nastavlja da se smanjuje zapremina geometrije SiGe tranzistora i povišava njegova granična (cutoff) frekvencija $\left(f_{T}\right)$, dolazi se do fundamentalnih fizičkih granica za ovu tehnologiju. Sadašnji nivo SiGe tehnološkog procesa ograničava efektivnu radnu frekvenciju negde u opsegu od 30 do $40 \mathrm{GHz}$.

Današnji troškovi vezani za proizvodnju RF kola u mobilnom terminalu su 
glavna barijera za najširu primenu bežičnih komunikacionih sistema i personalnih komunikacionih uređaja. Odskorašnje uvođenje SiGe legura u proizvodnju dovešće do zamene mnogo skupljih GaAs RF kola sa SiGe kolima koja imaju uporedive osobine i koja se proizvode po značajno nižoj ceni uz normalnu proizvodnju silicijuma. SiGe je poluprovodnička tehnologija razvijena za bežične aplikacije. Karakterišu je visoka brzina, visokofrekvencijske osobine potrebne za bežične komunikacije i poseduje potencijal za integrisanje analognih, RF i digitalnih funkcija u jednom integrisanom kolu (IC).

Primena SiGe je: u prednjem (frontend) dizajnu (DECT, CDMA, Bluetooth, ...), 5,8 GHz WLAN, u novim pojačavačima snage (WCDMA, 802.11, za proširen opseg Bluetooth-a, itd.), za GPS IC, za optičko umrežavanje do OC192 i dalje, i gotovo bilo koji tip bežičnih i RF komponenti.

Nadalje, 3G standard će usloviti povećavanje zahteva za minijaturizacijom RF kola, kao i ostalih delova poluprovodničkih kola unutar ručnog uređaja. Novi zahtevi za takvim proizvodima su niža cena i što viši nivo integracije kola, manja snaga ili veća brzina na manjoj struji, CMOS i RF pasivne komponente za RF CMOS pristup i uključivanje SiGe kao opcije sa minimumom dodatnih maski i kompatibilnošću sa $0,25 \mu \mathrm{m}$ standardnim CMOS procesom.

$\mathrm{Na}$ tržištu se mogu, između ostalog, pronaći 0,35 Micron SiGe BiCMOS proizvodi, čiji je radni napon 3,3 V. Kod ovog proizvođača optimizovan proces se odnosi na 3 NPN bipolarna elementa sa pojačanjem frekvencije $\left(\mathrm{f}_{\mathrm{T}}\right)$ po jedinici
62/40/25 GHz (HS/ST/HV) i pojačanjem snage frekvencije (Fmax) po jedinici 70/60/40 $\mathrm{GHz}$ na različitim probojnim BVceo naponima $(>2 / 3 / 5$ V). Duboka kanalna izolacija obezbeđuje superiornu imunost na šum u bipolarnim elementima, kritične karakteristike u RF dizajnu.

\section{Galijum-arsenid ( GaAs )}

Sa efektivnom masom elektrona koja je samo delić iste od silicijuma, GaAs poseduje bolje prenosne osobine. GaAs primenjen u realnim sklopovima postiže radne frekvencije i veće od $100 \mathrm{GHz}$. Dok silicijum ima prednosti pri primeni kod minijaturnih sklopova, GaAs može da radi na mikrotalasnim frekvencijama koje su daleko od $\mathrm{f}_{\mathrm{T}}$ za silicijum.

GaAs HBTs (heterojunction bipolar transistors - heterospojni bipolarni tranzistori) standardno se primenjuju kod pojačavača snage $u$ današnjim ćelijskim telefonima dok se GaAs HEMTs (high-electron mobility transistors - tranzistori visoke elektronske pokretljivosti) standardno primenjuju kod pojačavača snage u Ka opsegu u ćelijskim infrastrukturama.

Kao primer može poslužiti galijumarsenidno monolitno mikrotalasno IC (GaAs MMIC) CGY 92. Sa njim se značajno povećava vreme rada u rezervnom (stand-by) režimu mobilnih telefona. Uređaj obezbeđuje izlaznu snagu od $32 \mathrm{dBm}$ na $3 \mathrm{~V}$ do $35 \mathrm{dBm}$ na $5 \mathrm{~V}$. Može se koristiti u ručnim uređajima napravljenim za GSM (global system for mobile communications - globalni sistem mobilnih komunikacija) i svetski AMPS (advanced mobile phone service - napredni mobilni telefonski servis) standard. 
Za razliku od uobičajenih silicijumovih IC-a koji rade u režimu $\mathrm{C}$ klase, novi $25-\mathrm{GHz}$ uređaj, CGY 92, radi u režimu AB klase. Ovim se povećava opšta efikasnost sistema za $2 \mathrm{~dB}$, jer sistemi koji rade u režimu $\mathrm{AB}$ klase ne zahtevaju filtriranje između RF izlaznog stepena snage i antene sistema (što sistemi koji rade u režimu $\mathrm{C}$ klase zahtevaju). Svaki put kada se signal filtrira, gubi se snaga.

S obzirom da IC radi na nižim naponima do $2,7 \mathrm{~V}$ može se napajati sa samo tri baterijske ćelije. Ulazna impedansa je $50 \Omega$, a izlazna snaga se može podešavati.

IC je smešteno u MW12 pakovanje, koje je pogodna radio-frekvencijska modifikacija SOT 223 pakovanja.

\section{Indijum-fosfid ( InP )}

Sklopovi InP poseduju prednosti u odnosu na GaAs kod mnogih aplikacija i dostižu radne frekvencije iznad $300 \mathrm{GHz}$. Materijali bazirani na InP sastoje se od InP i legura InGaAs i InAlAs, podešenih na InP podlogu. Korišćenjem ovih materijala različiti slojevi strukture sklopa mogu biti optimizovani za pojedinačne parametre, što je ključno za sklopove visokih performansi. Kako InP ima nešto veću efektivnu masu, njegov opseg provodnosti strukture omogućava veće brzine kretanja elektrona na mnogo većim poljima u poređenju sa GaAs i InGaAs. To ima za posledicu da se InP koristi u sklopovima gde deluju velika polja, što značajno poboljšava osobine uređaja.

Jedan od kritičnih parametara kod HBT tranzistora u GaAs i InP je pobudni (turn-on) napon, prikazan na slici 1. HBT-i u InP imaju niži pobudni napon, što omogućava povećanje efikasnosti rada pojačavača i manju snagu disipacije. Dok nije

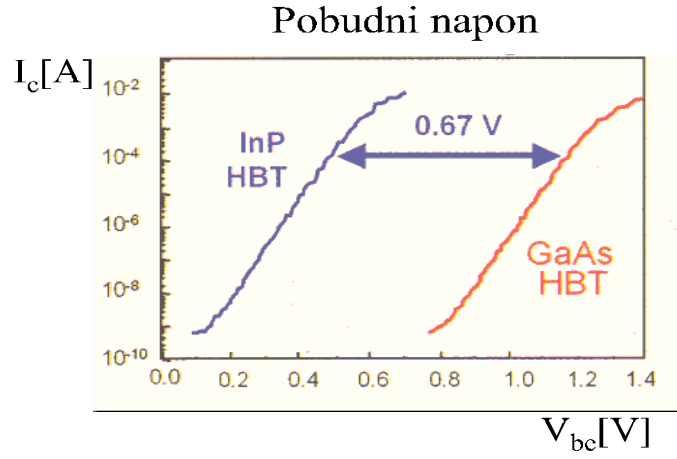

Sl. 1 - Struja kolektora Ic(A) u zavisnosti od napona baza-emiter $\operatorname{Vbe}(V)$

kritičan kod aplikacija sa optičkim vlaknima, manji pobudni napon smanjuje zahteve baterijskog napajanja (produžava vreme rada) za ručne bežične aplikacije.

U slučaju probojnog napona i GaAs i InP imaju značajne prednosti u odnosu na SiGe, kao što se vidi sa slike 2. GaAs može imati od 10 do 12 VDC probojni napon na graničnoj frekvenciji iznad 50 GHz. Ovo je idealna karakteristika za pojačavače snage i visokobrzinska digitalna kola koja se koriste u današnjim RF sistemima i proizvodima, kao i za njihovu primenu u uređajima budućnosti.

Ključna karakteristika kod naprednih visokoefikasnih pojačavača kod mikrotalasa i digitalnih kola za aplikacije sa optičkim vlaknima biće probojni napon.

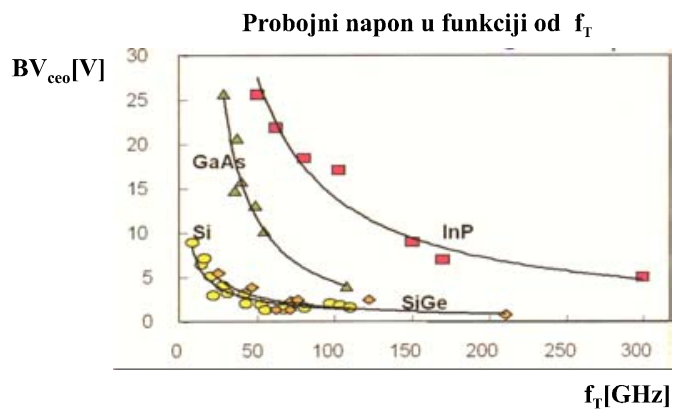

Sl. 2 - Probojni napon BVceo(V) u zavisnosti od granične frekvencije $f_{T}(\mathrm{GHz})$ 
InP je jedini poluprovodnički materijal za optičke komponente koji detektuje i emituje svetlost na 1,3 do 1,5 mikrona talasnim dužinama kod većine telekomunikacionih sistema sa optičkim vlaknima. Kao rezultat, InP HBT tranzistor može biti konstruisan sa integrisanim PIN fotodiodama, laserima i modulatorima. Ova osobina će olakšati proizvodnju monolitnih jedinstvenih čipova FO podsistema (kao što su prijemnici ili primopredajnici) kojima se dostižu brzine protoka od 40 ili čak $80 \mathrm{~Gb} / \mathrm{s}$. Kako montaža i pakovanje tipično čine 60 do $80 \%$ od cene poluprovodničkih optoelektronskih sklopova, monolitni primopredajnici nude mogućnost bitnog smanjenja cene kod budućih visokobrzinskih infrastruktura.

Uticaj parazitne kapacitivnosti na sveukupnu električnu impedansu unutar kola na ovim radnim frekvencijama može biti značajan i tako uticati na opšte osobine uređaja i njihovu efikasnost. S obzirom na ovo, razvijena je tehnika za minimizaciju parazitnih kapacitivnosti spoja baza - kolektor u InP HBT tranzistoru, kojom se značajno povećava njegova granična $\left(\mathrm{f}_{\mathrm{T}}\right)$ frekvencija i unapređuju visokobrzinske digitalne osobine, kao što je prikazano na slici 3 .

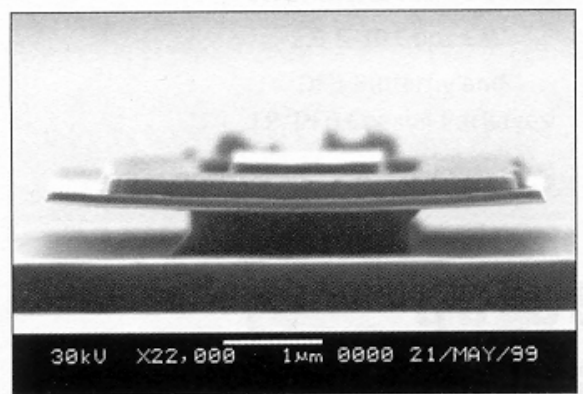

Sl. 3 - Slika spoja baza-kolektor u InP HBT tranzistoru
Kod novih kola za pojačavače snage susreće se sa sličnim izazovima. Ovde je obezbeđenje većeg propusnog opsega direktno povezano sa održavanjem linearnosti i poboljšanjem karakteristika za otklanjanje šuma. Tipičan dizajn novih kola karakteriše InP SHBT tranzistor sa InGaAs kolektorom koji radi kao PIN dioda sa širokopojasnim InP HBT raspodeljenim transimpedansnim pojačavačem. Ovim se uspešno održava ravnoteža između postignutih osobina i novih pakovanja, što se ogleda kroz nižu cenu za 40 $\mathrm{Gb} / \mathrm{s}$ optičke aplikacije, kao što je prikazano na slici 4. Ovakav monolitni fotoprijemnik obezbeđuje propusni opseg od $47 \mathrm{GHz}$ sa $38 \mathrm{~dB}-\Omega$ transimpedansom.

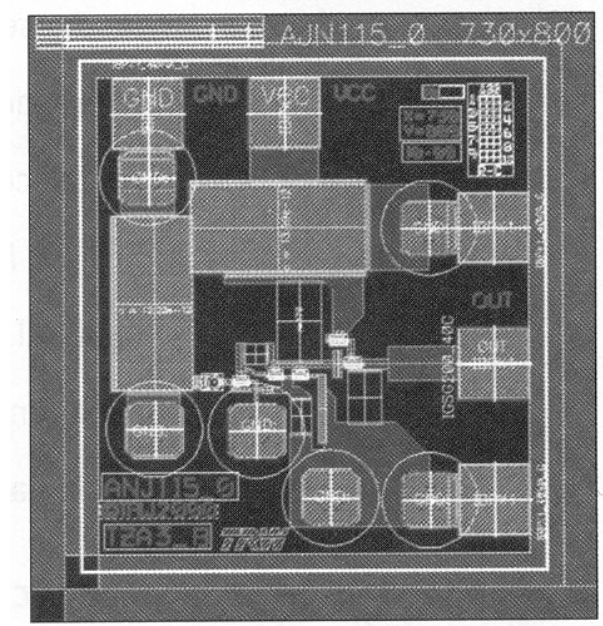

Sl. 4 - Matrica integrisanog InP SHBT fotoprijemnika

\section{Integracija kola i komponenti}

Savremeni projektanti RF uređaja rade na tome da izgrade kompletan 40 $\mathrm{Gb} / \mathrm{s}$ OE (Opto-Electronics - optička elektronika) prijemnik uključujući fotodiodu, transimpedansni pojačavač (TIA) i ograničavajući pojačavač na jednom či- 
pu koristeći InP. Ovakva integracija kola zahteva od projektanta da je kvalifikovan za analognu, digitalnu tehniku i tehniku mešovitim signalima. Modulacija signala pomoću optičkog nosioca u FO aplikacijama je analogna po prirodi, sa analognim signalom koji se konvertuje od digitalnog u predajniku i vraća $\mathrm{u}$ digitalan $\mathrm{u}$ prijemniku. RF komponente se nalaze sa obe strane veze, što zahteva projektovanje mešovitim signalima. InP je podesan za aplikacije sa mešovitim signalima zbog svog visokog probojnog napona, propusnog opsega i ujednačenosti praga osetljivosti.

Optičke komponente će obezbeđivati propusni opseg $3 \mathrm{~dB}$, dostižući radnu frekvenciju $48 \mathrm{GHz}$, pouzdanost u odnosu na šum manju od $12 \mathrm{pA} /(\mathrm{Hz})^{1 / 2}$ i izlazni napon 0,5 VDC od vrha do vrha. Za modulatorske pokretače (drivers) specifikacije su oštrije i zahtevaju propusne opsege veće od $48 \mathrm{GHz}$, izlazne napone veće od $3 \mathrm{~V}$ od vrha do vrha, vreme porasta (rise time) od najmanje $7 \mathrm{ps}$, pri čemu je u nekim konfiguracijama na raspolaganju samo jedan napon napajanja, dok je DC snaga ograničena.

Navedene osobine predstavljaju značajan izazov za projektante novih kola sa optičkim vlaknima kojima bi se postigle brzine protoka od $40 \mathrm{~Gb} / \mathrm{s}$ i veće. Uticaj parazitne kapacitivnosti na sveukupnu električnu impedansu unutar kola na ovim radnim frekvencijama je takav da može značajno da utiče na opšte osobine uređaja i njegovu efikasnost. S obzirom na to, razvijene su tehnike procesiranja kojima se minimizuju parazitne kapacitivnosti i povećava granična frekvencija.
Obezbeđenje većeg propusnog opsega kod novih kola za pojačavače snage je direktno povezano sa održavanjem linearnosti i poboljšanjem karakteristika za otklanjanje šuma. Korišćenjem poboljšanih pobudnih karakteristika InP HBT sa specijalno projektovanim kolektorom već sada se mogu primeniti u uređajima za mikrotalasne aplikacije sa $\mathrm{f}_{\mathrm{T}}$ od $80 \mathrm{GHz}$ ili više na $70 \mathrm{kA} / \mathrm{cm}^{2}$ sa $B_{\text {vceo }}$ $>18$ VDC. Ovo je daleko od mogućnosti dostupnih GaAs sklopova i više nego dovoljno za primenu kod aplikacija pojačavača snage u Ka-opsegu.

\section{Pakovanje sklopova}

Kod pakovanja nove generacije visokobrzinskih sklopova projektant mora obratiti posebnu pažnju na projekat pakovanja da bi se smanjile induktivnosti veza čipa i pri kontroli pakovanja, indukovana rezonansa. Otežavajuća okolnost pri projektovanju pakovanja koja sadrže optičke komponente je termički menadžment. Izazovnije od termičkog menadžmenta su RF osobine upakovanog dela. Umešnost u elektromagnetnom modelovanju pomoću simulacionog softvera je obavezna za optimizaciju osobina gotovog sklopa zbog međusobnog uticaja pakovanja, čipa i veza čipa. Da bi se optimizovale veze za visoke brzine induktivne parazitivnosti moraju biti minimizovane. To se postiže minimizacijom i odgovarajućim podešavanjem dužine veza. Kompenzacija kapacitivnih struktura dodatno može redukovati induktivnost. Sve to mora biti potpuno izvedeno u pakovanju, što omogućava nižu cenu tehnika asembliranja. 


\section{Testiranje kola}

Testiranje monolitnih mikrotalasnih integrisanih kola (MMIC), koja rade na najvišim granicama mogućnosti, približava rad RF projektanata radu inženjera specijalizovanih za testiranja. Instrumenti koji su danas komercijalno dostupni mogu da podrže prekidačka kola na radnim frekvencijama do $40 \mathrm{GHz}$, s tim da su vreme porasta (rise time) i vreme opadanja (fall time) mnogih InP sklopova često brža od istih vremena ispitne opreme. Da bi se direktno izmerila vremena porasta i opadanja ovakvih sklopova potrebna je ispitna oprema koju karakterišu četiri puta brža vremena porasta i opadanja od istih vremena sklopa koji se testira. S obzirom na navedeno, razvijene su tehnike testiranja sa kojima se ovakvi problemi pri ispitivanju sklopova prevazilaze. Jedna od ovih tehnika je opisana u radu [1].

\section{Evolucija CMOS tehnologije u Evropi}

Da bi se Evropa zadržala na pravcu prednjačenja u poluprovodničkoj tehnologiji, evropska komisija (Europien Commission) će zasnovati integralni projekat nazvan NANOCMOS. Cilj projekta je pionirski, a odnosi se na neophodne promene vezane za materijale, procese, arhitekturu sklopova i spojeve, da bi se nastavilo pomeranje granica vezanih za osobine poluprovodnika i njihovu gustinu.

Učesnici projekta će se obavezati da demonstriraju mogućnosti $45 \mathrm{~nm}$ CMOS logičke tehnologije u 2005. godini, dok će istovremeno započeti istraživanja no- ve generacije 32 i $22 \mathrm{~nm}$ tehnoloških čvorišta. Današnja manja tehnološka čvorišta se nalaze u granicama postojećih tehnologija, ali se očekuje da rezultati NANOCMOS projekta otvore put ka potpuno novim aplikacijama za informaciono društvo.

Partneri u ovom projektu su tri najveće evropske kompanije koje se bave poluprovodničkom tehnologijom: Infineon, Philips i STMicroelectronics; dva najveća evropska instituta za tehnološka istraživanja: CEA Leti (Francuska) i IMEC (Belgija); tri istraživačke laboratorije koordinisane od FhG (Nemačka); osam istraživačkih laboratorija koordinisanih od CNRS (Francuska); jedna istraživačka laboratorija sa Tehničkog univerziteta Chemnitz (Nemačka); tri kompanije: Ion Beam Services (Francuska), ISILTEC (Nemačka) i Magwel (Belgija); i ACIES Europe (Francuska), koji će preuzeti neke aspekte menadžmenta projekta. Drugi partneri bi mogli da se uključe u konzorcijum u budućnosti.

Očekuje se da će prva faza rada na projektu trajati 27 meseci i mobilisaće veliki istraživački potencijal. Sa dodatnih $24 \mathrm{M}$ eura, koji će biti podrška od evropske komisije, partneri će, takođe, investirati napredne istraživačke resurse da bi ispunili ciljeve projekta.

\section{Zaključak}

S obzirom na zahteve tržišta, mogućnosti savremenih materijala i tehnologija od projektanata naprednih RF i FO sistema zahtevaće se posedovanje i korišćenje širih znanja i iz oblasti novih materijala, kao što su SiGe i InP, tehnika i 
tehnologija, kao i korišćenje viših nivoa integracije kola, novih pakovanja i testiranja, jer se samo kroz njihovu interakciju u procesu projektovanja i izrade sklopova može doći do odgovora na zahteve tržišta za novim proizvodima.

Razvoj tehnologije u 21. veku biće određen interakcijom između zahteva tržišta za novim aplikacijama i tehnologije. RF projektanti se nalaze pred izborom mnogih tehnoloških procesa $\mathrm{i}$ materijala koji bi mogli da odgovore tim zahtevima i koje bi trebalo na svrsishodan način kombinovati radi napretka.

Literatura:

[1] Striet, D.: The changing landscape of RF and fiber optics, RF Design, march 2002.

[2] www.sige, decembar 2003.

[3] www.sige.com, decembar 2003.

[4] Droinet, Y.: Advanced RF Technologies for the Wireless Market, Microwave Journal, september 2001.

[5] Vollmer, A.: Siemens GaAs MMIC keeps mobile phones operating longer, ELECTRONICS, vol. 67, 24 oktober 1994.

[6] Europe Sows Seeds for CMOS Technology Evolution, Microwave Journal, vol. 47, No. 5, may 2004. 